\title{
Total Synthesis of (-)-Spongidepsin
}

Laurent Ferrié, Sébastien Reymond, Patrice Capdevielle and Janine Cossy*

ESPCI, Laboratoire de Chimie Organique, 10 Rue Vauquelin, 75231 Paris Cedex 05, France

Supporting Information: ${ }^{1} \mathrm{H}$ and ${ }^{13} \mathrm{C}$ NMR spectra 


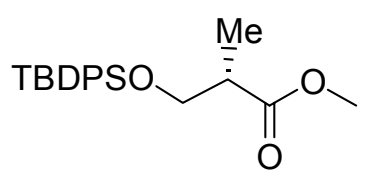

\section{Compound (1)}

$\left(\mathrm{CDCl}_{3}, 400 \mathrm{MHz}\right)$

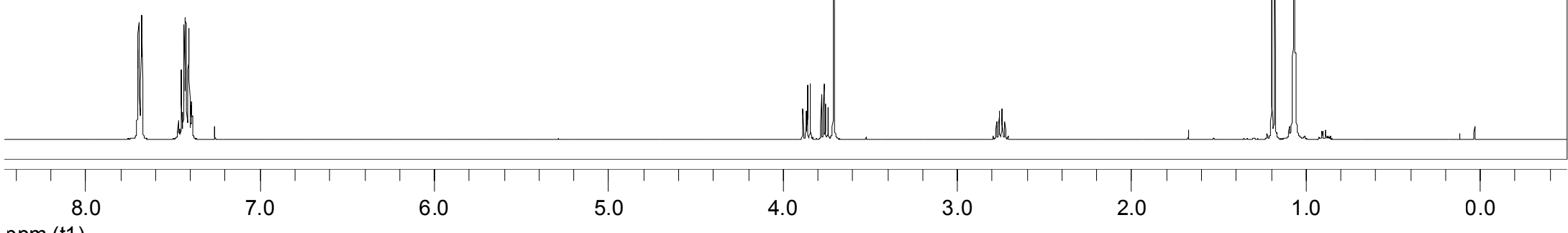

ppm (t1)

S-18 


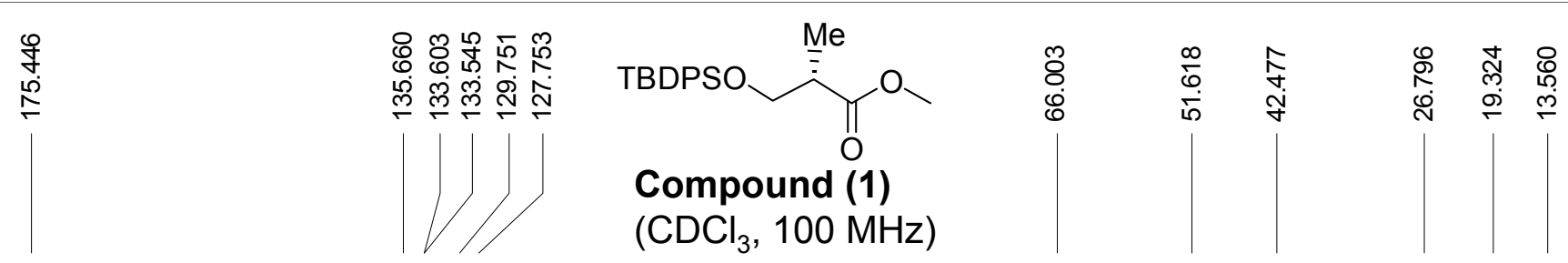

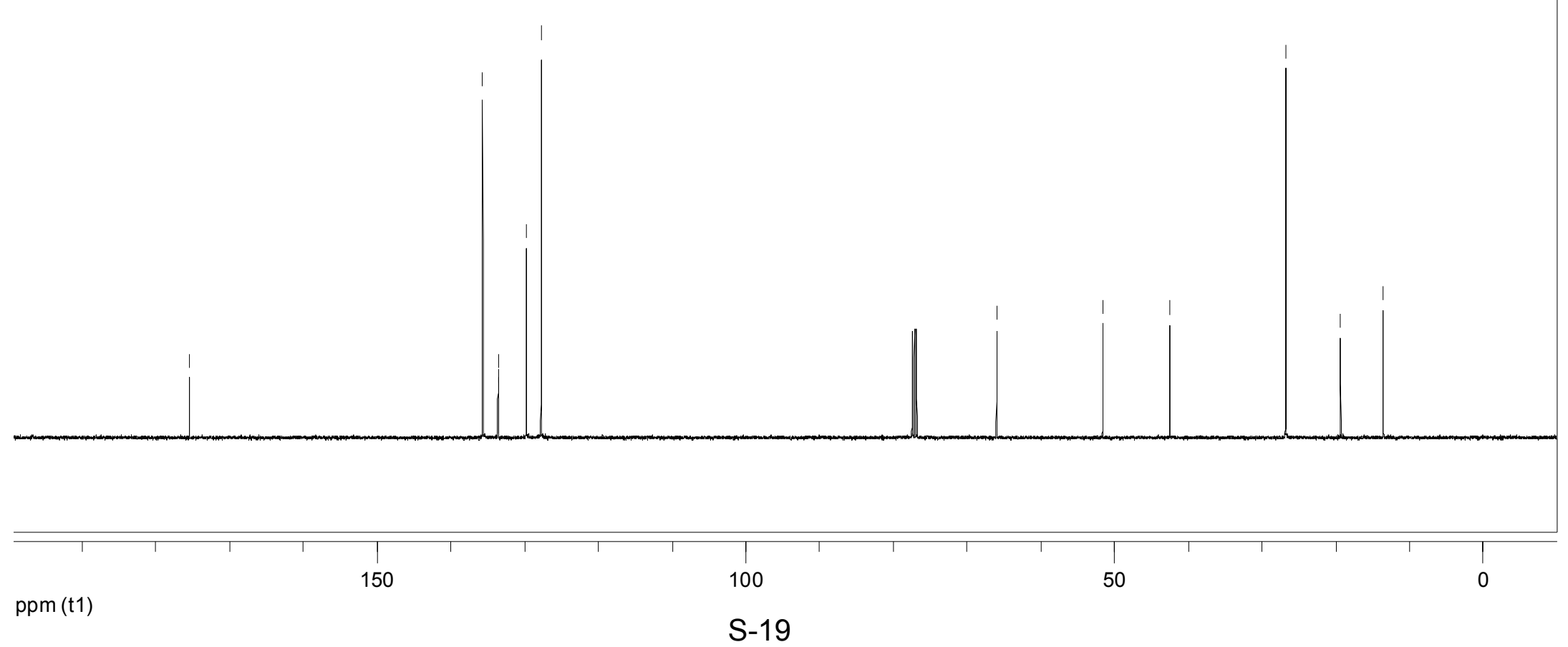




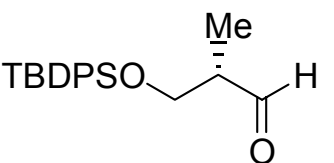

Compound (2)

$\left(\mathrm{CDCl}_{3}, 400 \mathrm{MHz}\right)$

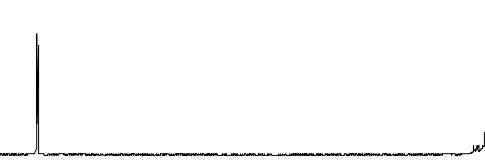

ppm (t1)

S-20 


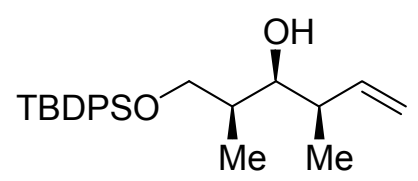

Compound (3)

$\left(\mathrm{CDCl}_{3}, 400 \mathrm{MHz}\right)$

ppm (t1)

6.0

$\begin{array}{cccccc}\mid & \mid & \mid & \mid & \mid & \mid \\ 5.0 & & & & & 4.0\end{array}$

S-21 


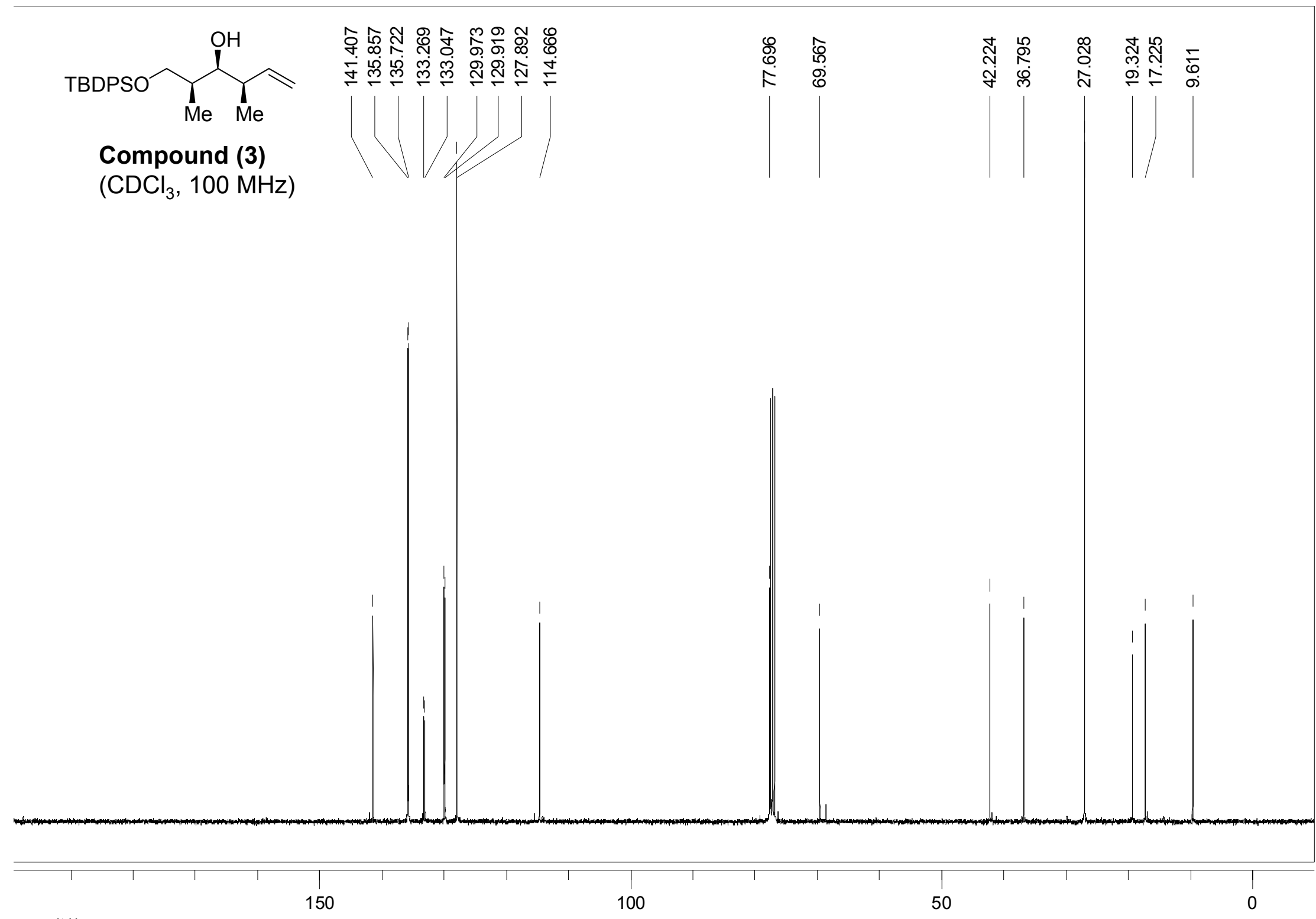

ppm (t1)

S-22 


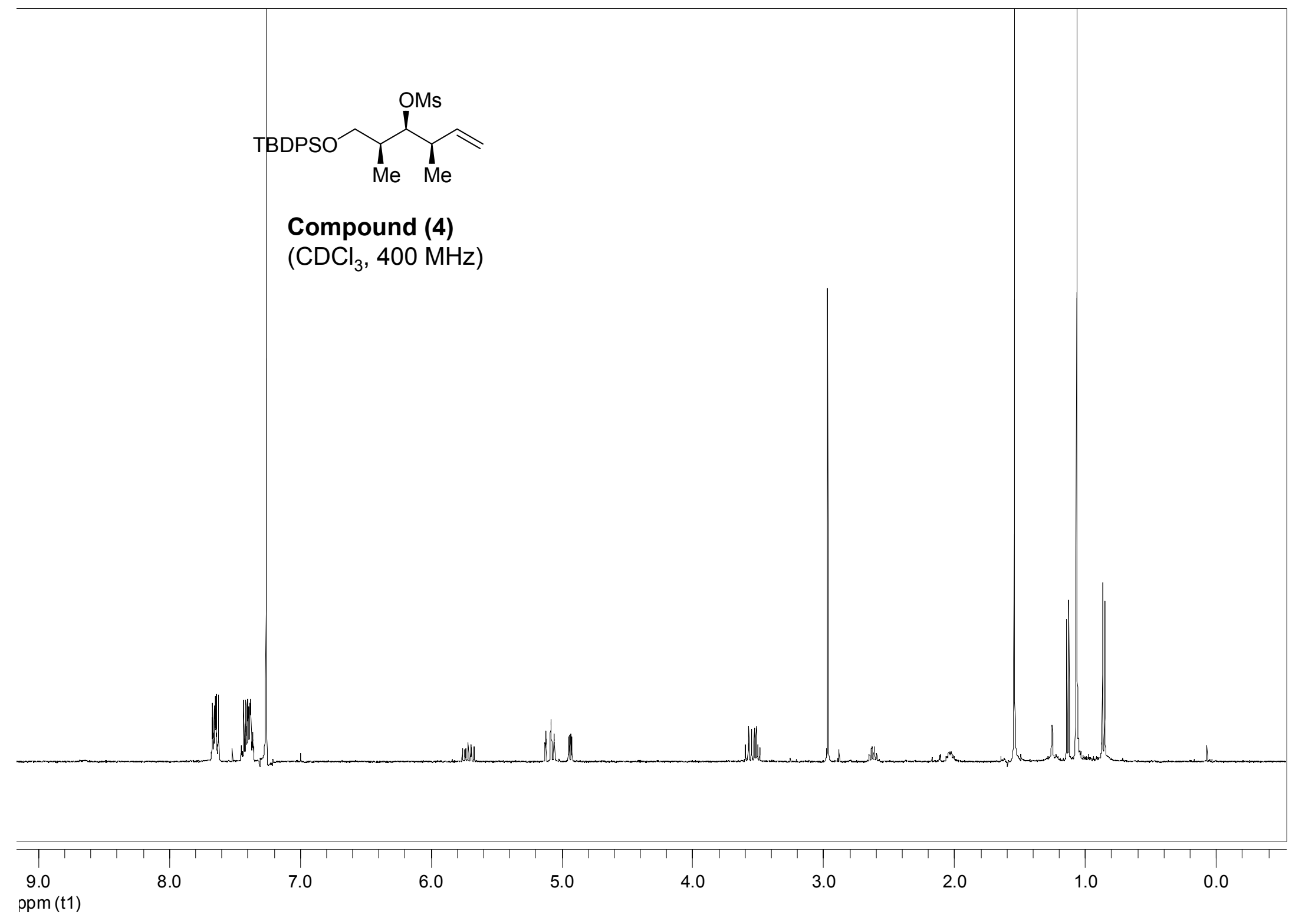

S-23 


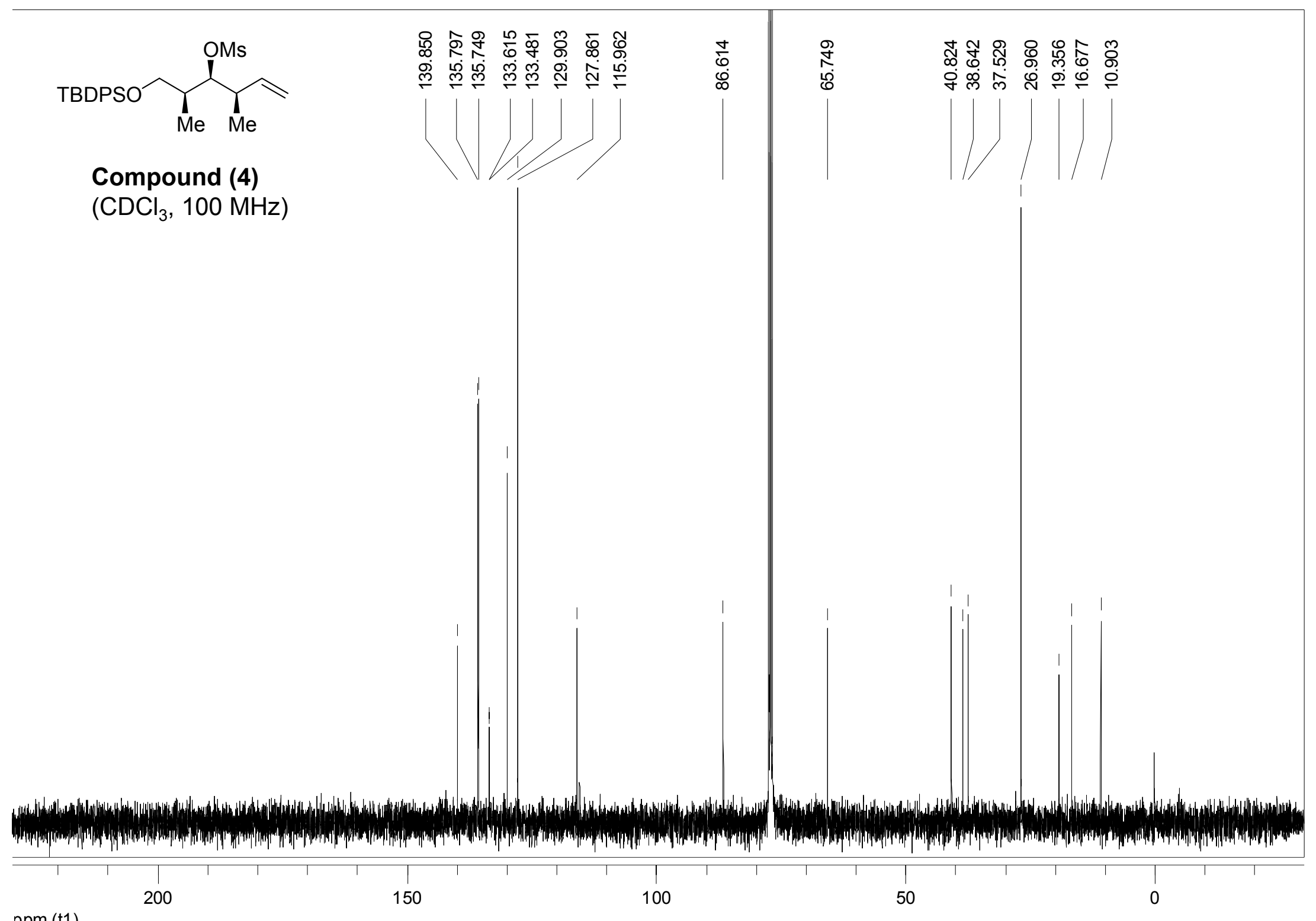

S-24 


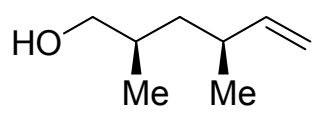

\section{Compound (5)}

$\left(\mathrm{CDCl}_{3}, 400 \mathrm{MHz}\right)$

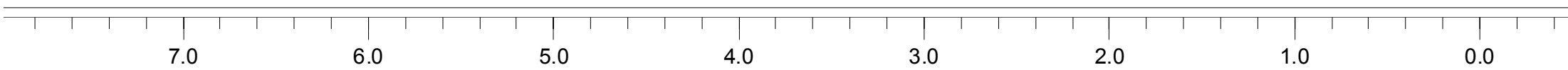

ppm (t1)

\section{S-25}




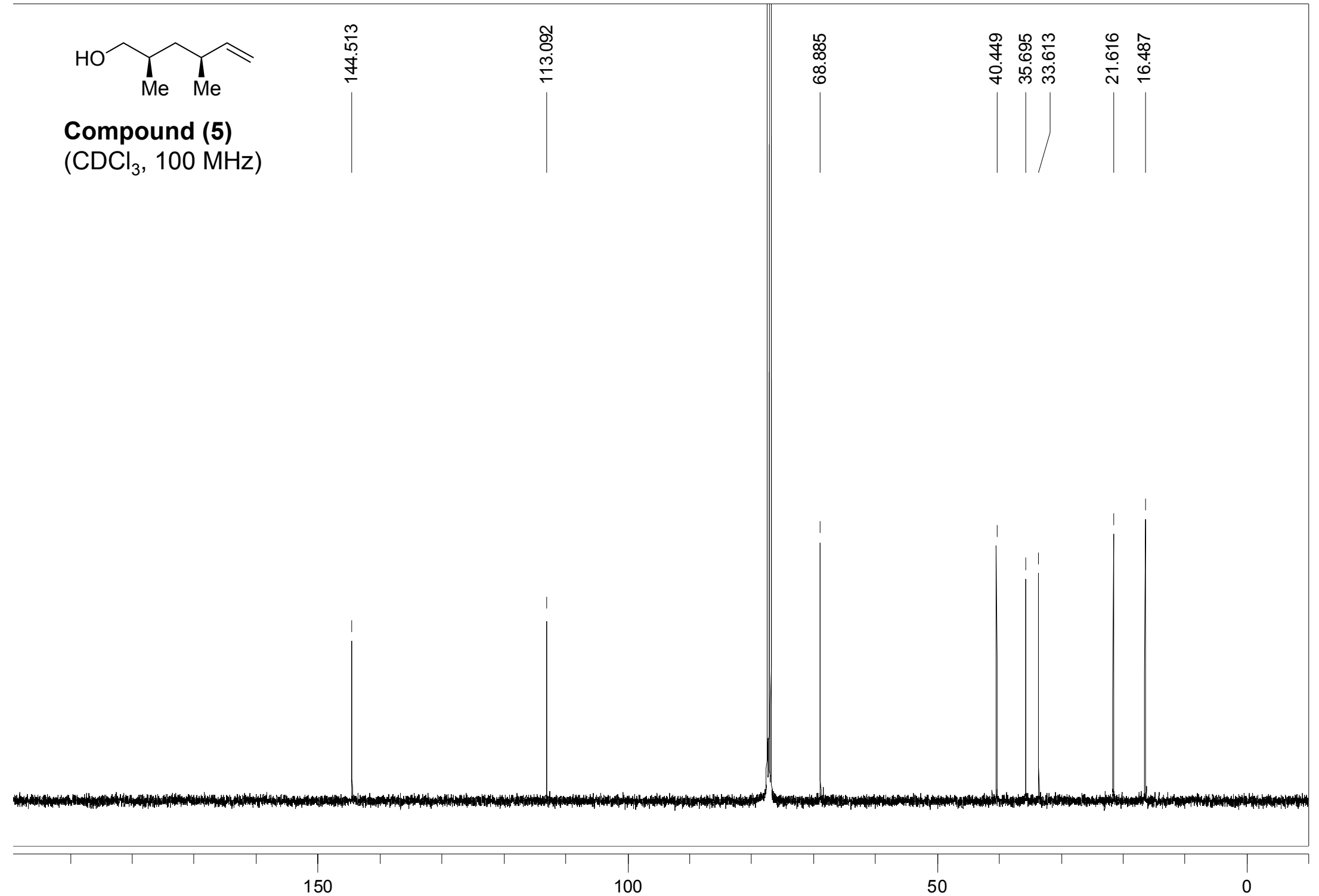

ppm (t1)

\section{S-26}


<smiles>C=CC(C)CC(C)C(=O)O</smiles>

\section{Compound (6)}

$\left(\mathrm{CDCl}_{3}, 400 \mathrm{MHz}\right)$

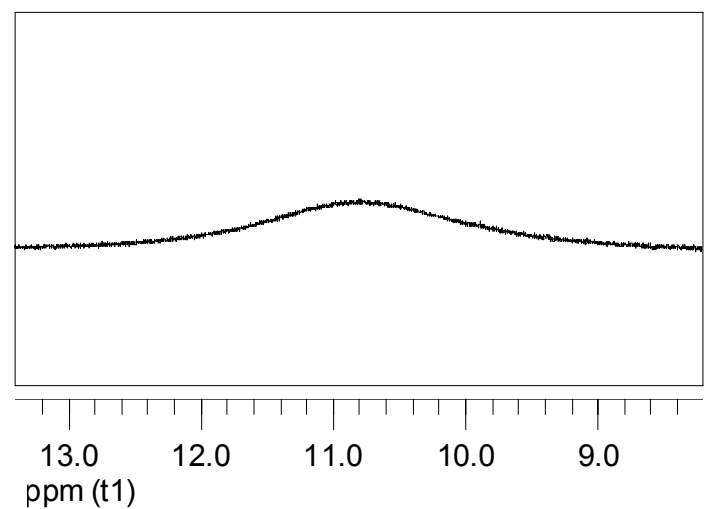

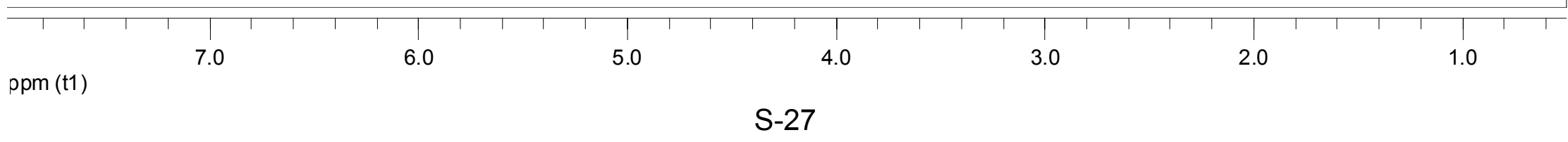




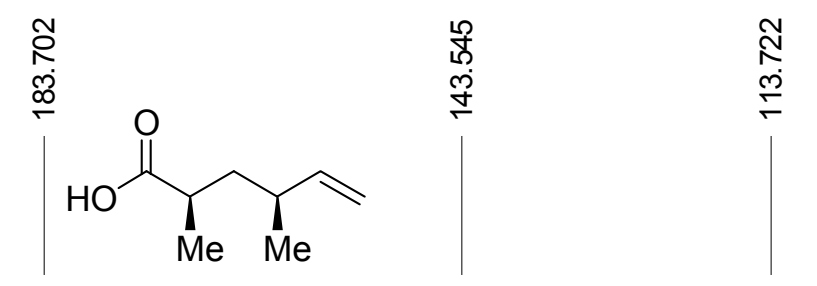

Compound (6)

$\left(\mathrm{CDCl}_{3}, 100 \mathrm{MHz}\right)$

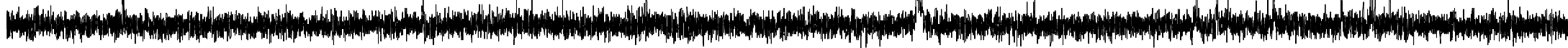

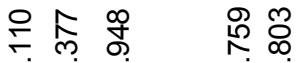

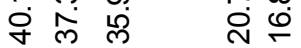

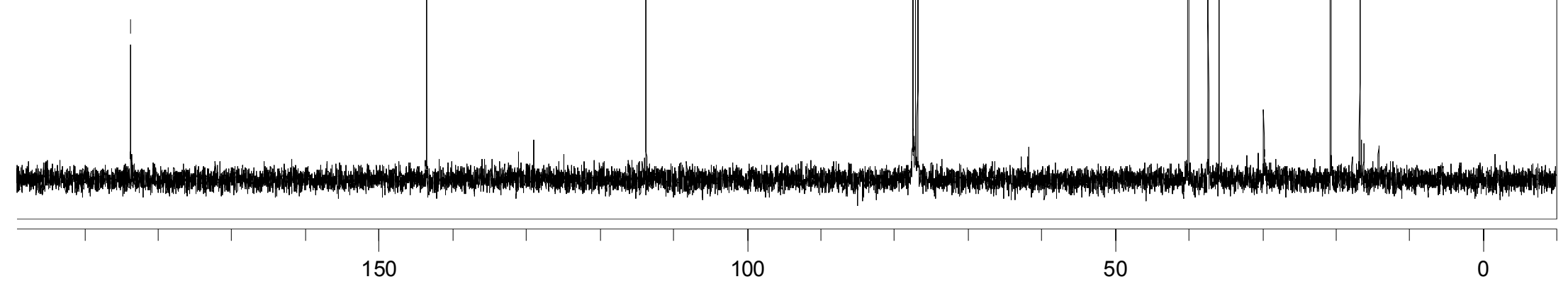

$\mathrm{ppm}(\mathrm{t} 1)$

S-28 


$$
\text { OTBDPS }
$$

Compound (8)

$\left(\mathrm{CDCl}_{3}, 400 \mathrm{MHz}\right)$

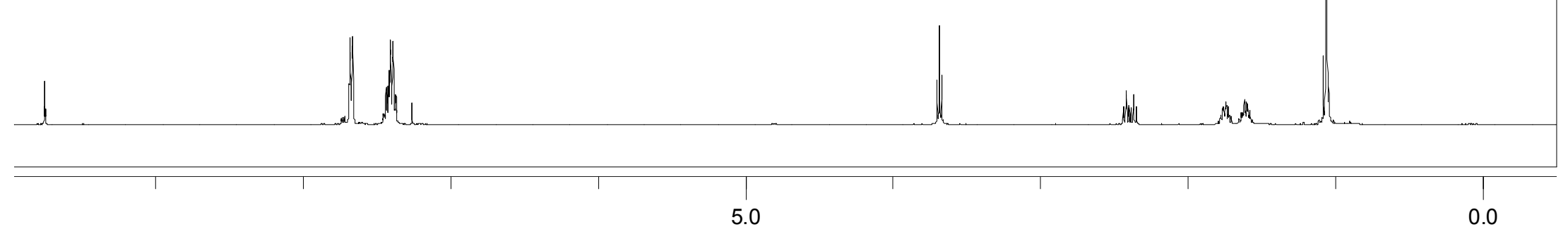

ppm (t1)

S-29 


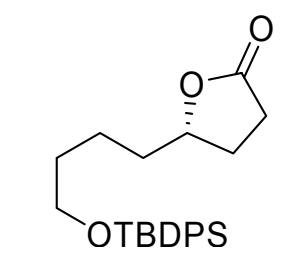

Compound (9)

$\left(\mathrm{CDCl}_{3}, 400 \mathrm{MHz}\right)$

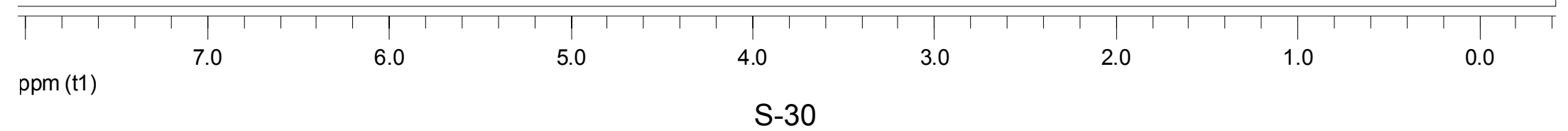




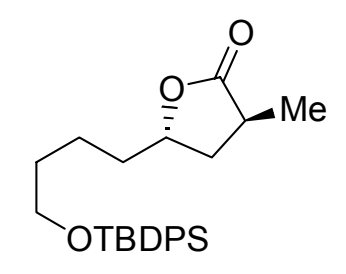

Compound (10)

$\left(\mathrm{CDCl}_{3}, 400 \mathrm{MHz}\right)$

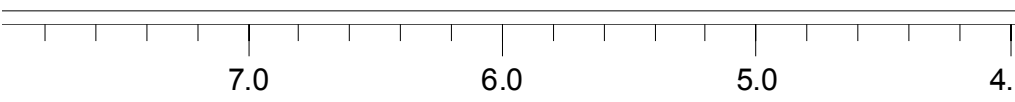

ppm (t1)

4.0

3.0

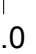

2.0

1.0

S-31 


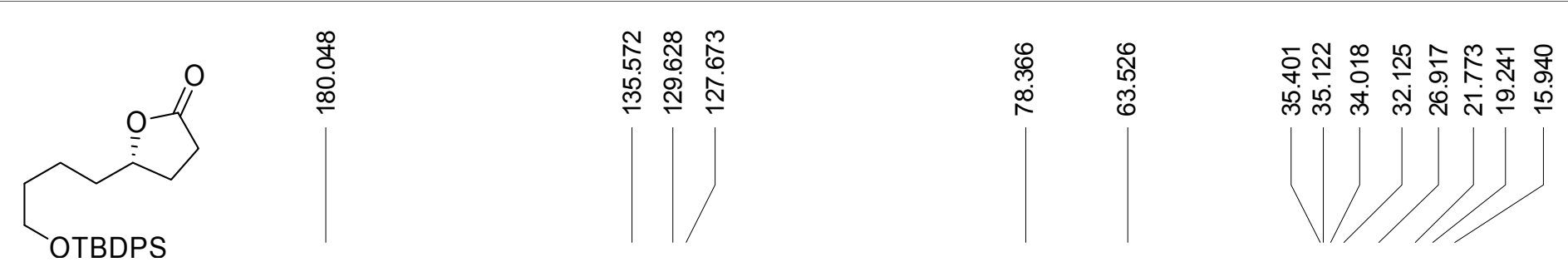

\section{Compound (9)}

$\left(\mathrm{CDCl}_{3}, 100 \mathrm{MHz}\right)$

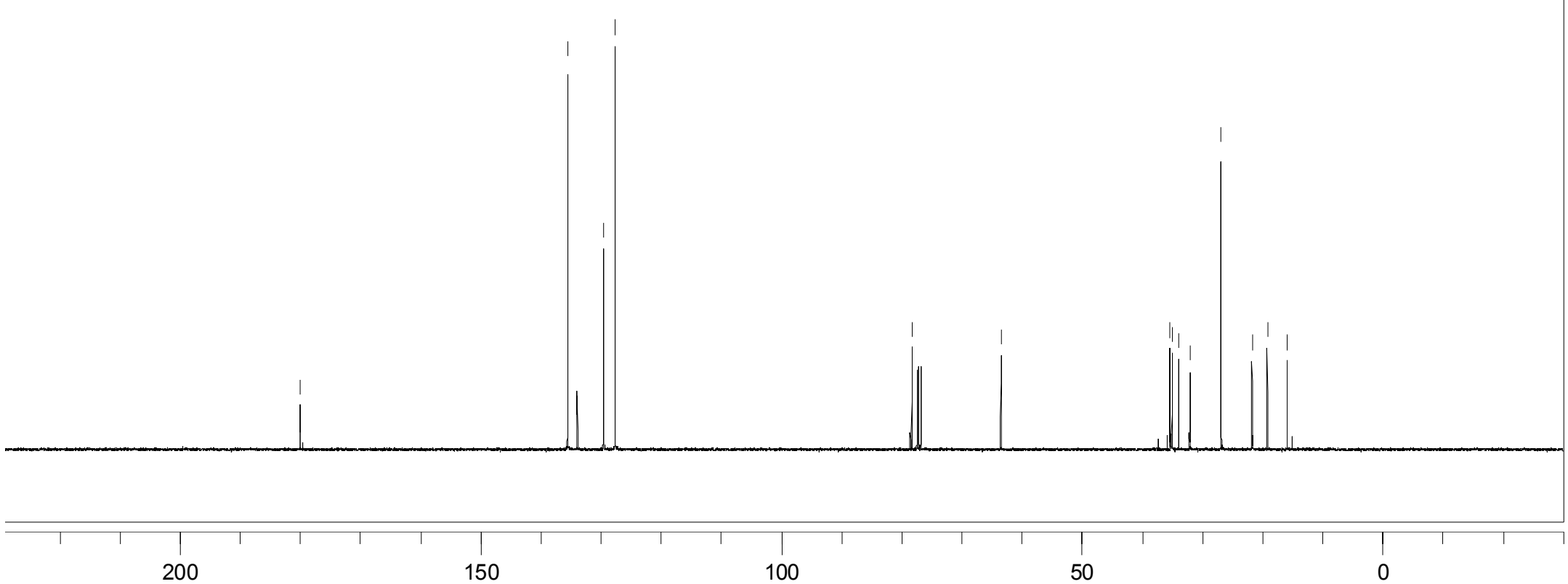

ppm (t1)

S-32 


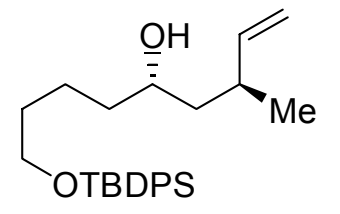

Compound (11)

$\left(\mathrm{CDCl}_{3}, 400 \mathrm{MHz}\right)$

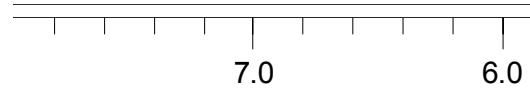




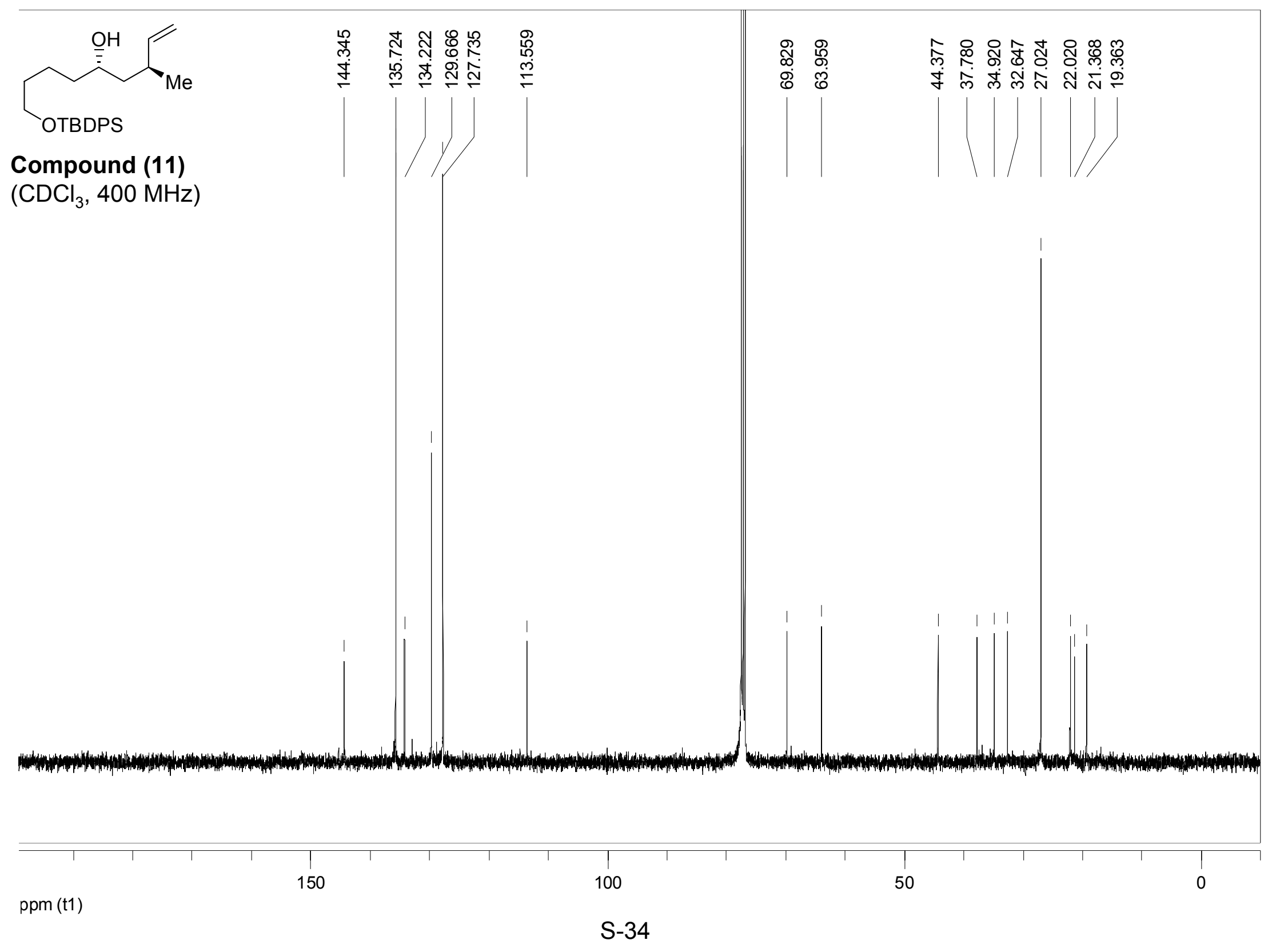




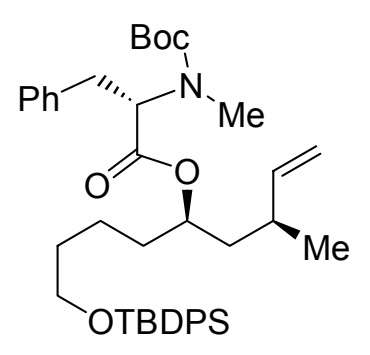

\section{Compound (12)}

$\left(\mathrm{CDCl}_{3}, 400 \mathrm{MHz}\right)$ 


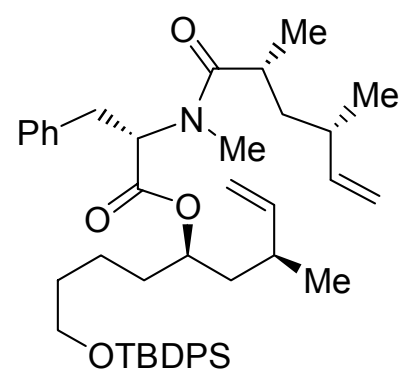

\section{Compound (13)}

$\left(\mathrm{CDCl}_{3}, 400 \mathrm{MHz}\right)$

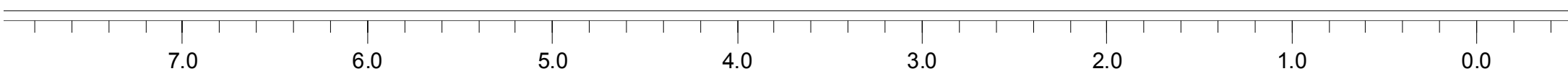

ppm (t1)

S-36 


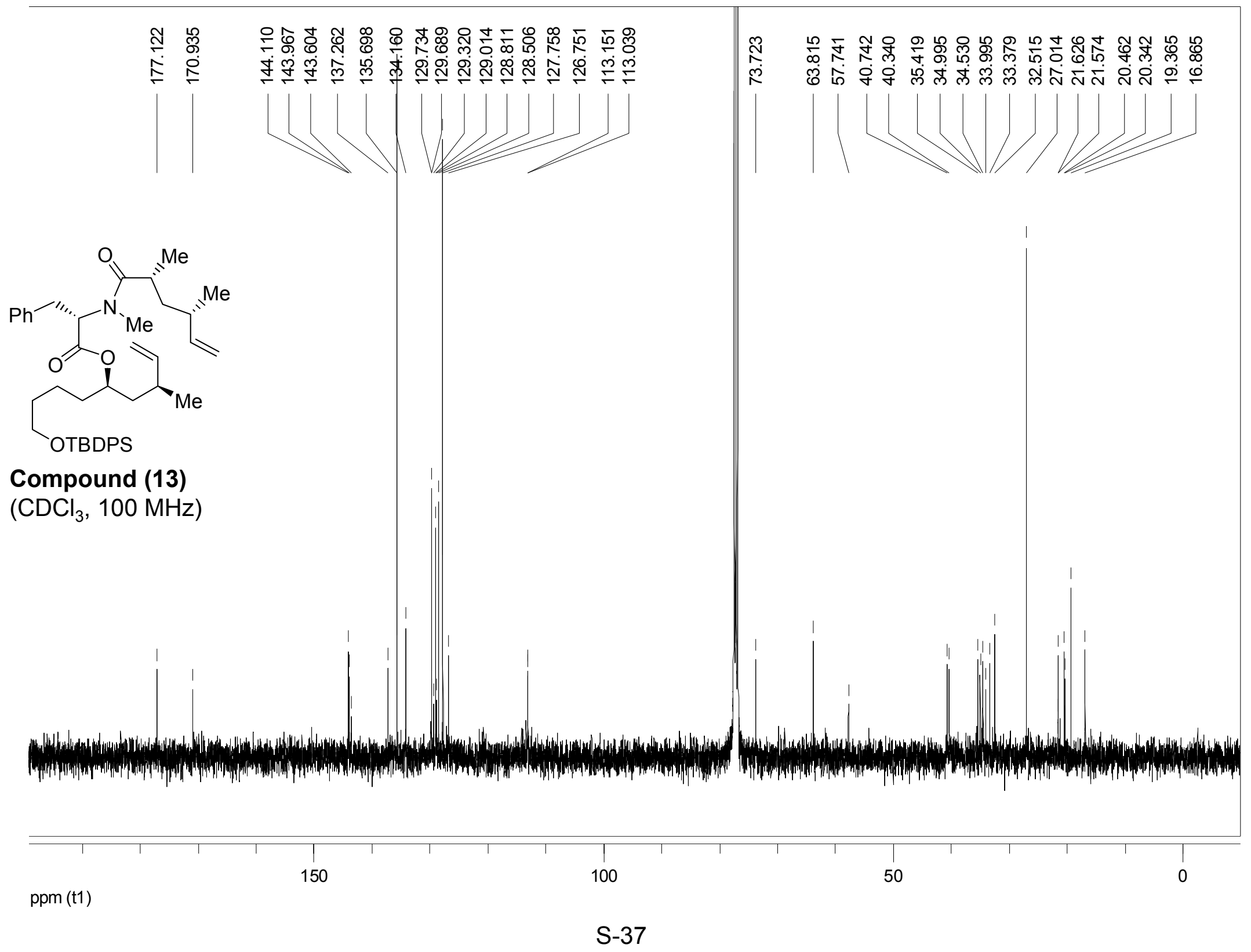




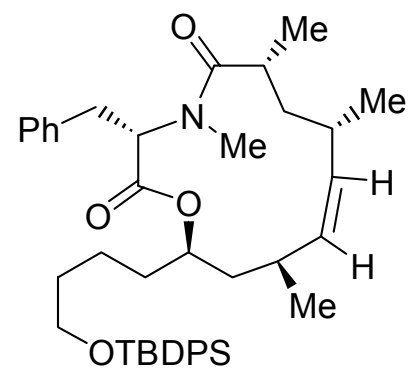

Compound (14)

$\left(\mathrm{CDCl}_{3}, 400 \mathrm{MHz}\right)$

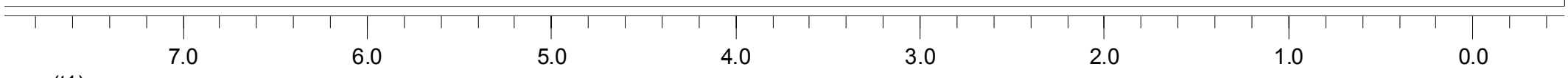

ppm (t1)

S-38 


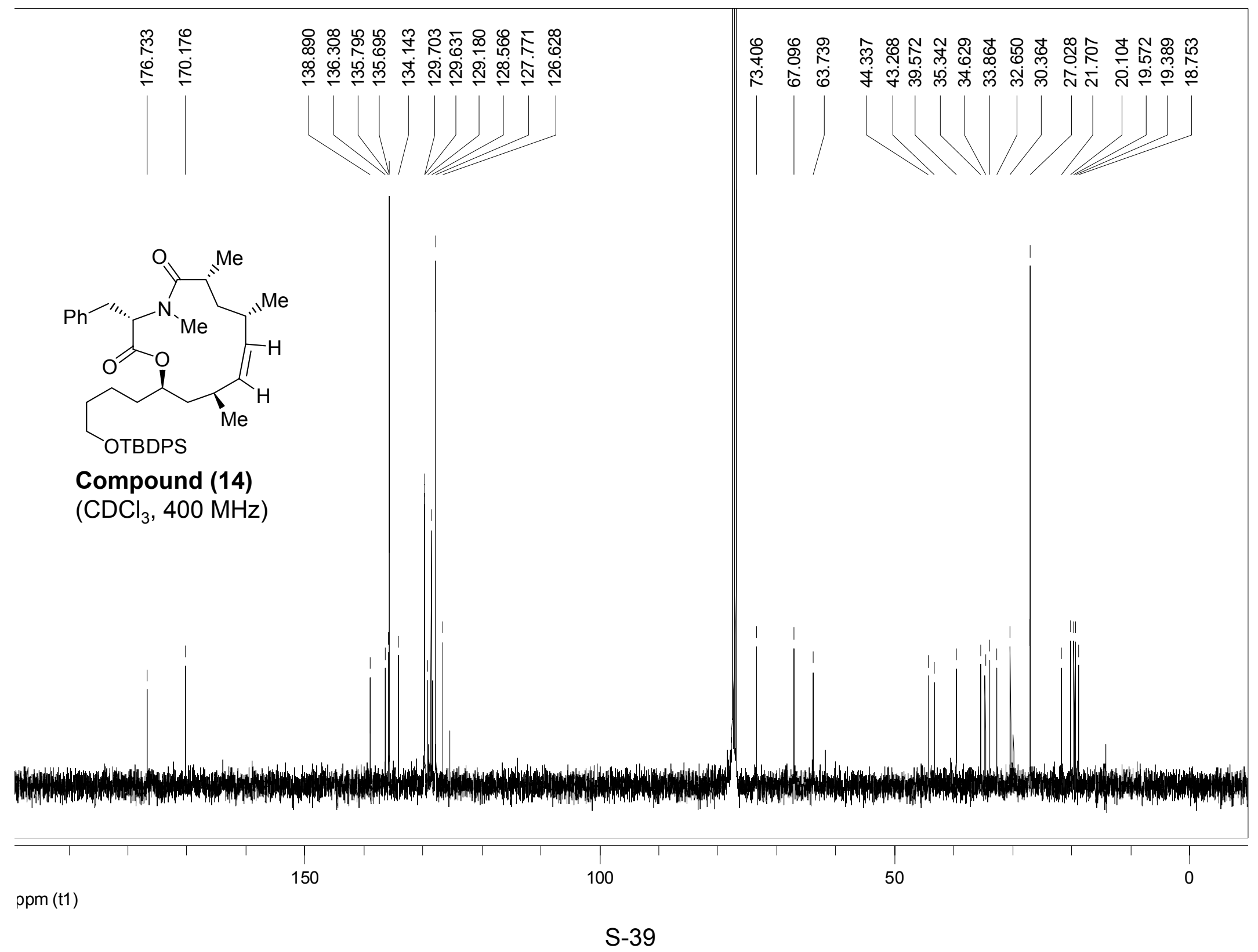




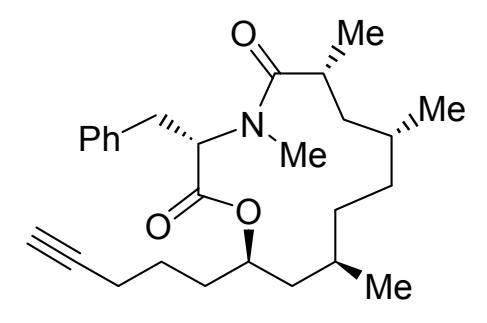

Synthetic

(2R, 4S, 7S, 9S)-(-)-Spongidepsin

$\left(\mathrm{CD}_{3} \mathrm{OD}, 400 \mathrm{MHz}\right)$

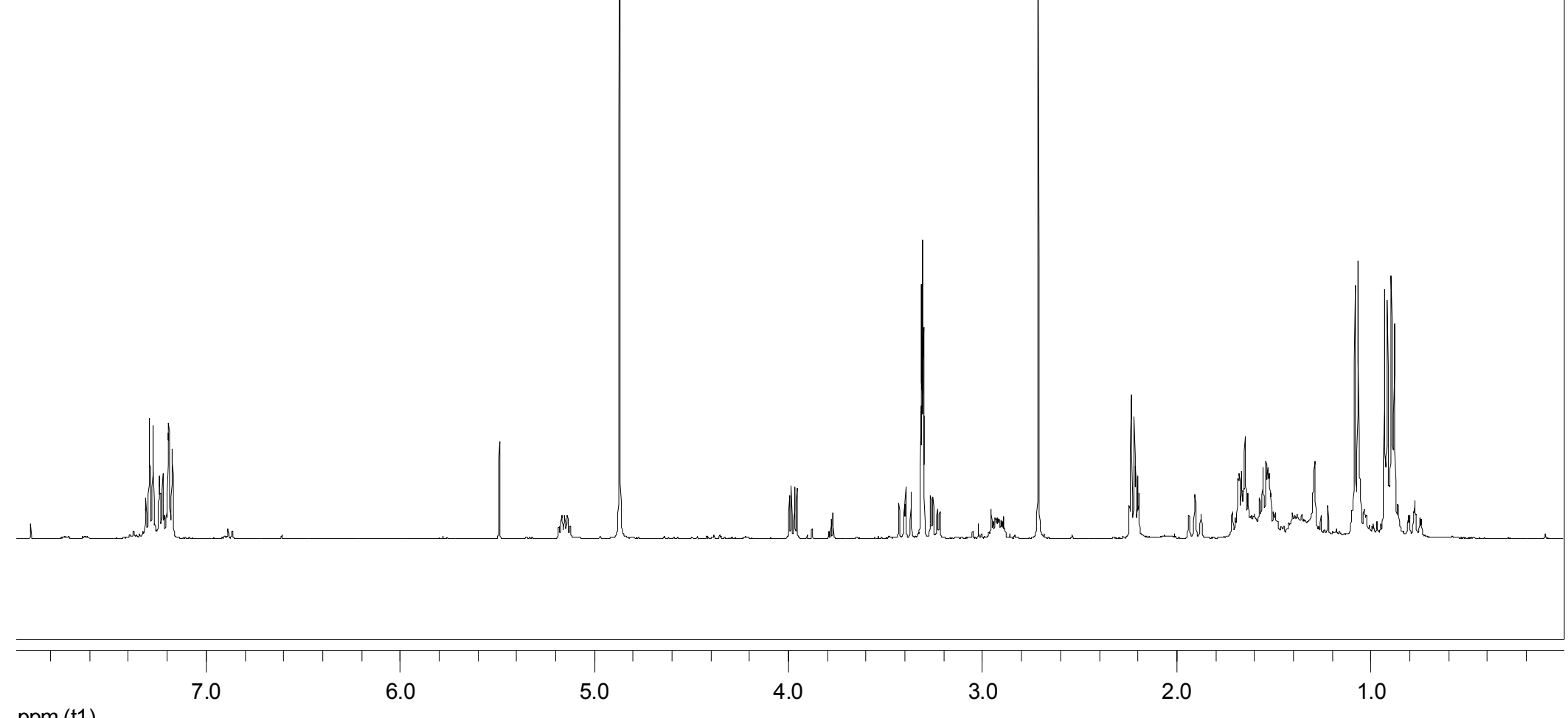




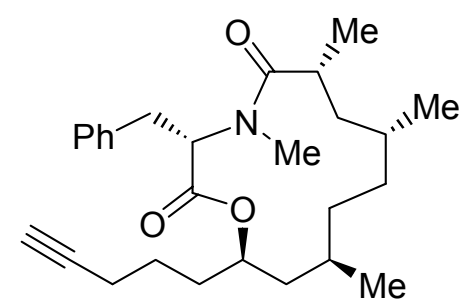

Synthetic

(2R, 4S, 7S, 9S)-(-)-Spongidepsin

$\left(\mathrm{CDCl}_{3}, 400 \mathrm{MHz}\right)$

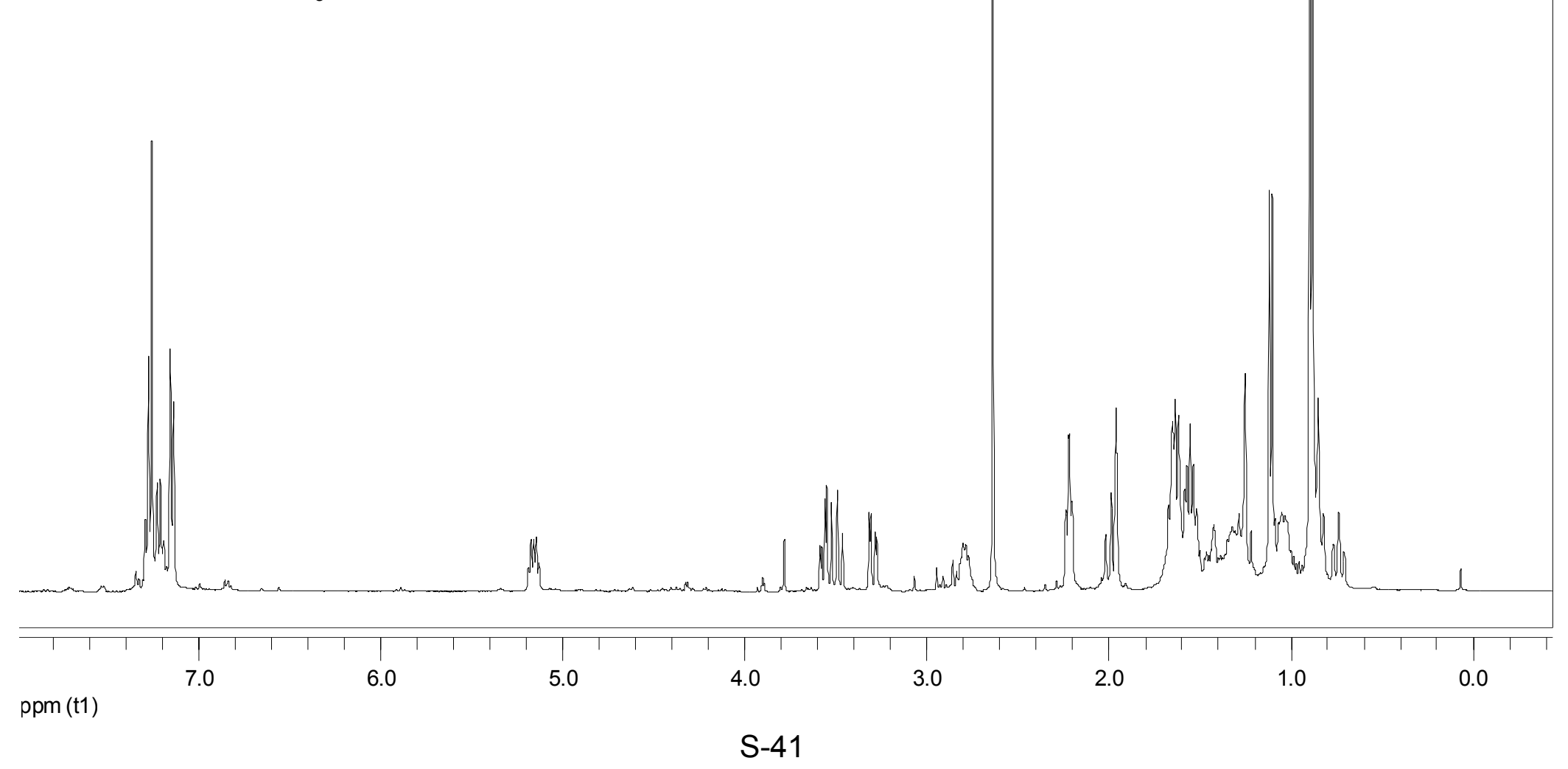



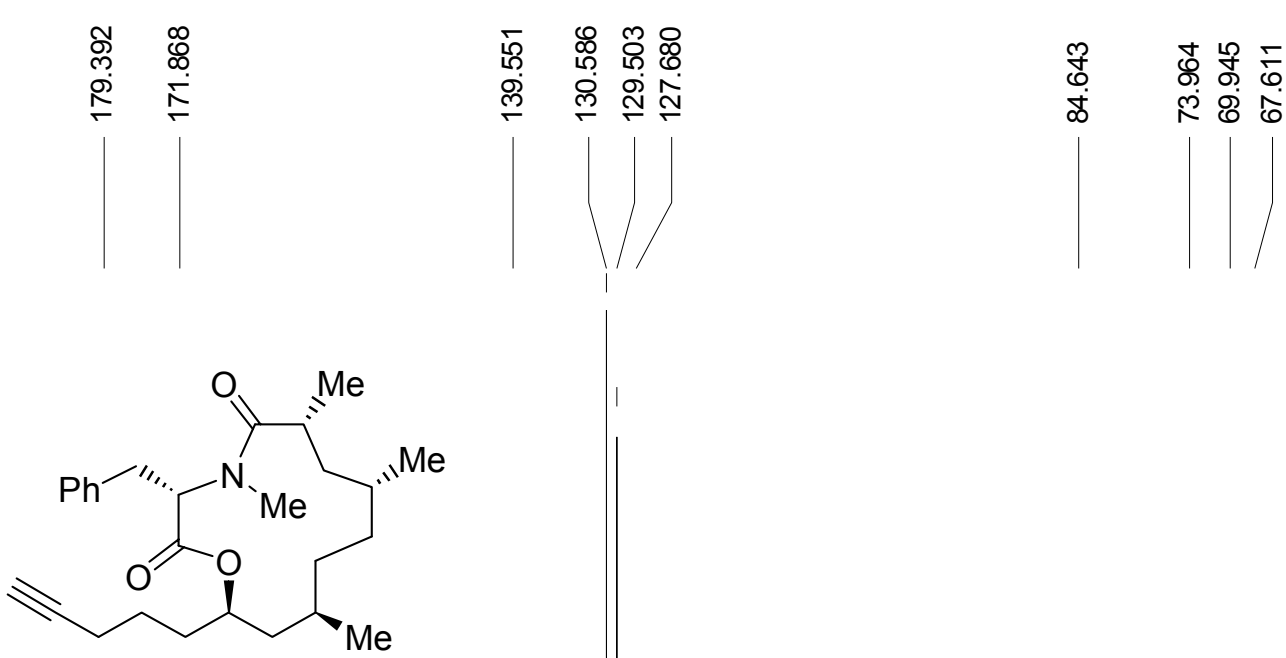

\section{Synthetic}

(2R, 4S, 7S, 9S)-(-)-Spongidepsin

$\left(\mathrm{CD}_{3} \mathrm{OD}, 100 \mathrm{MHz}\right)$

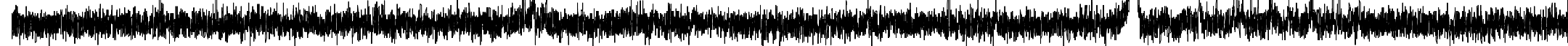

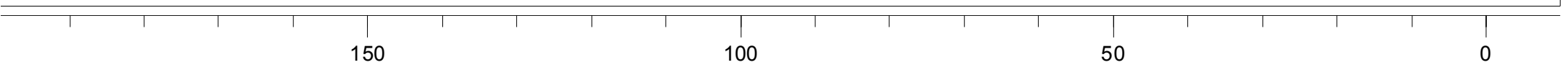

ppm (t1) 